\title{
In silico analysis of diverse endophytic fungi by using ITS1-5,8S-ITS2 sequences with isolates from various plant families in Brazil
}

\author{
S.A. Rhoden, A. Garcia, J.L. Azevedo and J.A. Pamphile \\ Departamento de Biotecnologia, Genética e Biologia Celular, \\ Universidade Estadual de Maringá, Maringá, PR, Brasil \\ Corresponding author: J.A. Pamphile \\ E-mail: prof.pamphile@gmail.com
}

Genet. Mol. Res. 12 (2): 935-950 (2013)

Received August 6, 2012

Accepted January 16, 2013

Published April 2, 2013

DOI http://dx.doi.org/10.4238/2013.April.2.10

\begin{abstract}
Brazil has a great diversity of plants, and considering that all plant species studied to date have endophytic microorganisms (bacteria or fungi), the country is a resource in the search for bioactive compounds. Endophytes live within plants without causing damage and may be in dynamic equilibrium with the health of the plant. Endophytic fungi can be identified by sequencing the region corresponding to internal transcribed spacer 1-5,8S-internal transcribed spacer 2 ribosomal DNA, and carrying out phylogenetic analyses of these sequences helps to identify species. The objective of this research was to perform in silico phylogenetic analysis of fungi isolated from various plant families in Brazil. For this study, we chose 12 articles published between 2005 and 2012 that examined endophytes isolated in Brazil. We analyzed sequences deposited in the National Center for Biotechnology Information GenBank database and carried out alignment to determine the genetic distance of strains using the Molecular Evolutionary Genetics Analysis version 5 program. The articles yielded 73 plant species belonging to 13 families found in the Brazilian States of Amazonas, Bahia, Minas Gerais, Paraná, and São Paulo. The use of
\end{abstract}


GenBank and the Molecular Evolutionary Genetics Analysis program for phylogenetic observation revealed that several endophytes had been incorrectly identified because inconsistencies were apparent in their location in the phylogenetic tree. However, approximately $98 \%$ of the sequences deposited in GenBank were consistent with the identification of related genera, indicating that the database is sufficiently robust to support future studies, in which molecular identification of endophytes is made via analysis of ribosomal DNA sequences.

Key words: Endophytic fungi; Phylogenetic analysis; ITS1-5,8S-ITS2; Family plants; Brazil; DNA barcoding

\section{INTRODUCTION}

Brazil has the richest flora in the world. It includes more than 56,000 species of plants - nearly $19 \%$ of the world's flora (Ministério do Meio Ambiente, 2002). Currently, 100,000 fungus species have been described, and this number is increasing by approximately $1.2 \%$ per year. In every plant studied thus far, the presence of at least one endophyte has been confirmed, signaling broad biological diversity and the discovery of new species. Therefore, endophytic fungi are a promising area of study in Brazil and other tropical areas.

The endophyte-plant interaction may have arisen because of co-evolutionary processes during the appearance of higher plants hundreds of millions of years ago (Strobel et al., 1996; Pamphile and Azevedo, 2002). Strobel (2003) reported that evidence of these associations has been discovered in fossilized tissues of stems and leaves. These endophytic microorganisms may have developed genetic systems that allowed the transfer of information to and from higher plants. Jasinski and Payette (2007) reported microorganisms associated with higher plants in fossilized conifer tissues, suggesting that these organisms may have coevolved with them.

These microorganisms provide many advantages to their hosts related to plant growth and protection against illness, insect attack, phytopathogenic fungi, and other pests. These effects are due to substances produced by endophytes that occupy ecological niches similar to those occupied by plant pathogens. The interactions between plants and microorganisms have been known for a long time; however, the presence of endophytes within the plant opens new perspectives for studies of these interactions, because unlike pathogens, these organisms do not cause disease in plants. Although endophyte-host interactions are not yet well understood, many cases of symbiosis may be characterized by neutral or antagonistic interactions (Azevedo et al., 2000; Souza et al., 2004).

Several endophytic fungi have been isolated and studied in Brazil, in which the tropical climate is a positive selective natural force for endophyte diversity and a richness of flora is present. Although knowledge of the ecology, life history, and phylogeny of endophytic fungi has increased and accumulated rapidly in recent decades, details about their evolutionary origin, speciation, and ecological roles have not yet been fully revealed (Saikkonen et al., 2004). Therefore, knowing the number of species of fungi and their phylogenetic distribution is an important tool for elucidating the pattern and time of fungal diversification as well as the complexity of ecosystems (Arnold et al., 2007; Higgins et al., 2007; Arnold et al., 2009). 
Endophytes are being intensively studied because they have properties that can be applied in various areas, and they are potentially useful in agriculture, biological control, and the development of bioactive compounds, studies of which have indicated that their presence in large numbers can reduce attacks by insects (Kogel et al., 2006; Koulman et al., 2007) and pathogenic fungi in host plants (Azevedo et al., 2000). Information has been uncovered through bioprospecting, which includes the critical stage of identifying endophytes with molecular techniques as internal transcribed spacer (ITS)1-5,8S-ITS2 sequencing analysis and the study of diversity using the National Center for Biotechnology Information (NCBI) GenBank database, the Basic Local Alignment and Search Tool (BLAST), and the Molecular Evolutionary Genetics Analysis (MEGA) program. Arnold et al. (2007) concluded that GenBank matches, if based on well-identified taxa, can be sufficient for estimating species richness and upperlevel taxonomic placement. However, the prevalence of unnamed samples in GenBank, the presence of misidentified taxa, and the rapid growth of the database - which translate to highly divergent matches at the genus and family levels when BLAST results from year to year are compared - underscore the need for caution when estimating taxonomic composition based on BLAST results alone. According to Palsson (2000), the term in silico biology refers to the use of computers to perform biological studies. Several researchers have used in silico approaches for genetics analysis (Chen et al., 2005; Bellemain et al., 2010; Gilbert et al., 2011; Victoria et al., 2011). Bellemain et al. (2010) explored the potential amplification biases that various commonly used ITS primers might introduce during the amplification of various parts of the ITS region in samples containing mixed templates ("environmental barcoding"). They have performed in silico polymerase chain reaction analyses with commonly used primer combinations using various ITS datasets obtained from public databases as templates. They conclude that ITS primers have to be selected carefully, especially when used for high-throughput sequencing of environmental samples.

The objectives of the present study were to analyze the diversity of endophytic fungus isolated from plants in Brazilian territories by using phylogenetic analysis from sequences deposited in GenBank, to correlate the endophytes with the families of plants in which they were isolated, and to validate the use of ITS1-5,8S-ITS2 sequencing. We sought to evaluate the effectiveness of ribosomal DNA (rDNA) sequencing for fungal identification and molecular diversity studies through in silico analysis.

\section{MATERIAL AND METHODS}

\section{Sequences}

To perform the phylogenetic analysis, we used data from articles recorded in the Coordenação de Aperfeiçoamento de Pessoal de Nível Superior - CAPES Periodics database. We selected 12 studies from Brazil published between 2005 and 2012. All studies had used sequencing of the ITS1-5,8S-ITS2 region of rDNA to identify endophytes. These 12 studies covered 73 species of plants distributed in 13 families: Orchidaceae, Rubiaceae, Euphorbiaceae, Malvaceae, Meliaceae, Solanaceae, Asteraceae, Fabaceae, Rutaceae, Anacardiaceae, Myrtaceae, Viscaceae, and Poaceae. The plants were from the following Brazilian States: Amazonas, Bahia, Minas Gerais, São Paulo, and Paraná (Figure 1). The ITS1-5,8S-ITS2 sequences of endophytic fungi were acquired through GenBank from NCBI. 


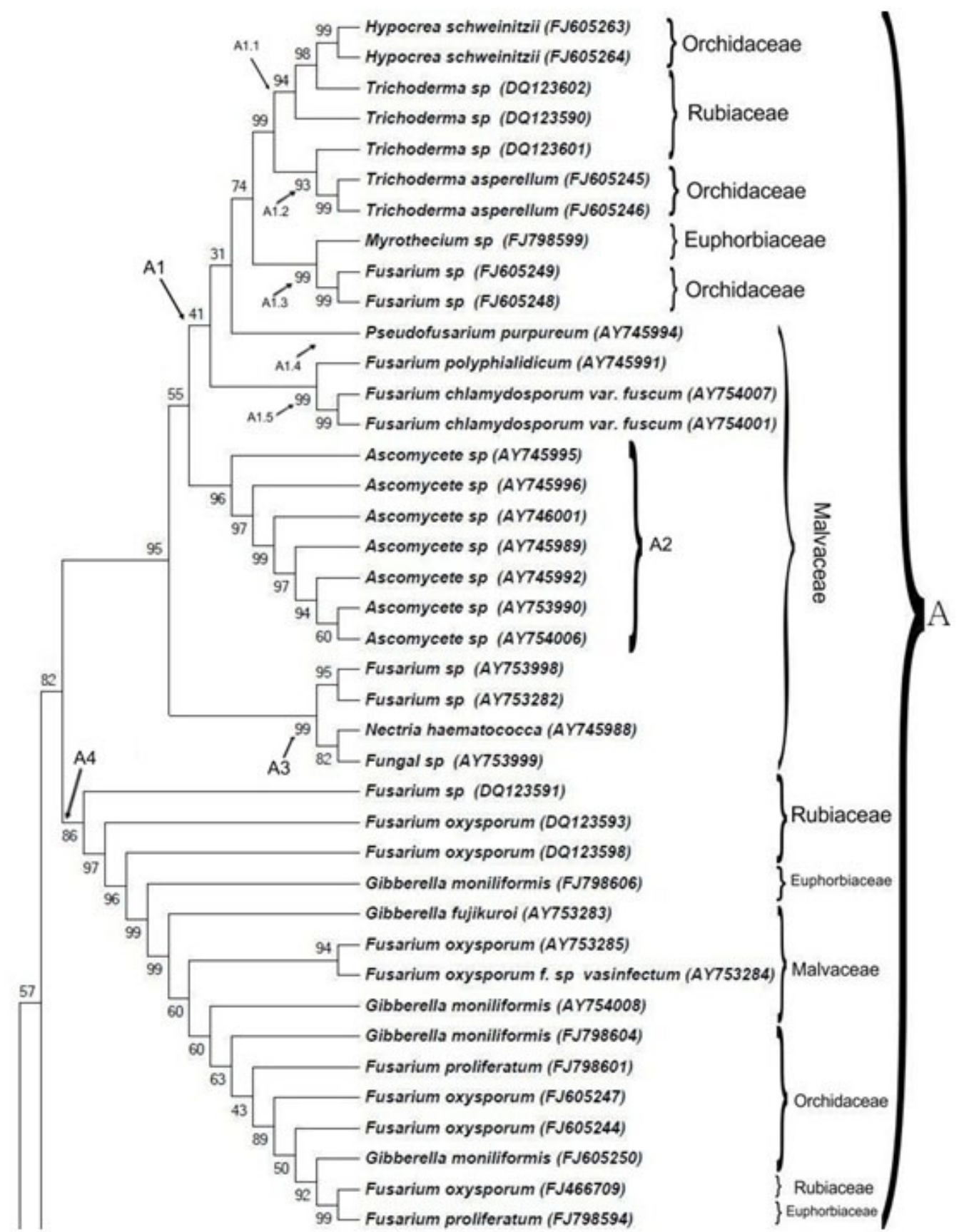

Figure 1. Phylogenetic analysis. The sequences determined were aligned by using the MEGA program (version 5.0; Tamura et al., 2011), with grouping by the NJ method (Saitou and Nei, 1987) using a p-distance matrix for nucleotides with the pairwise gap deletion option adopted and with 1000 bootstrap repetitions.

Continued on next page 
Figure 1. Continued.

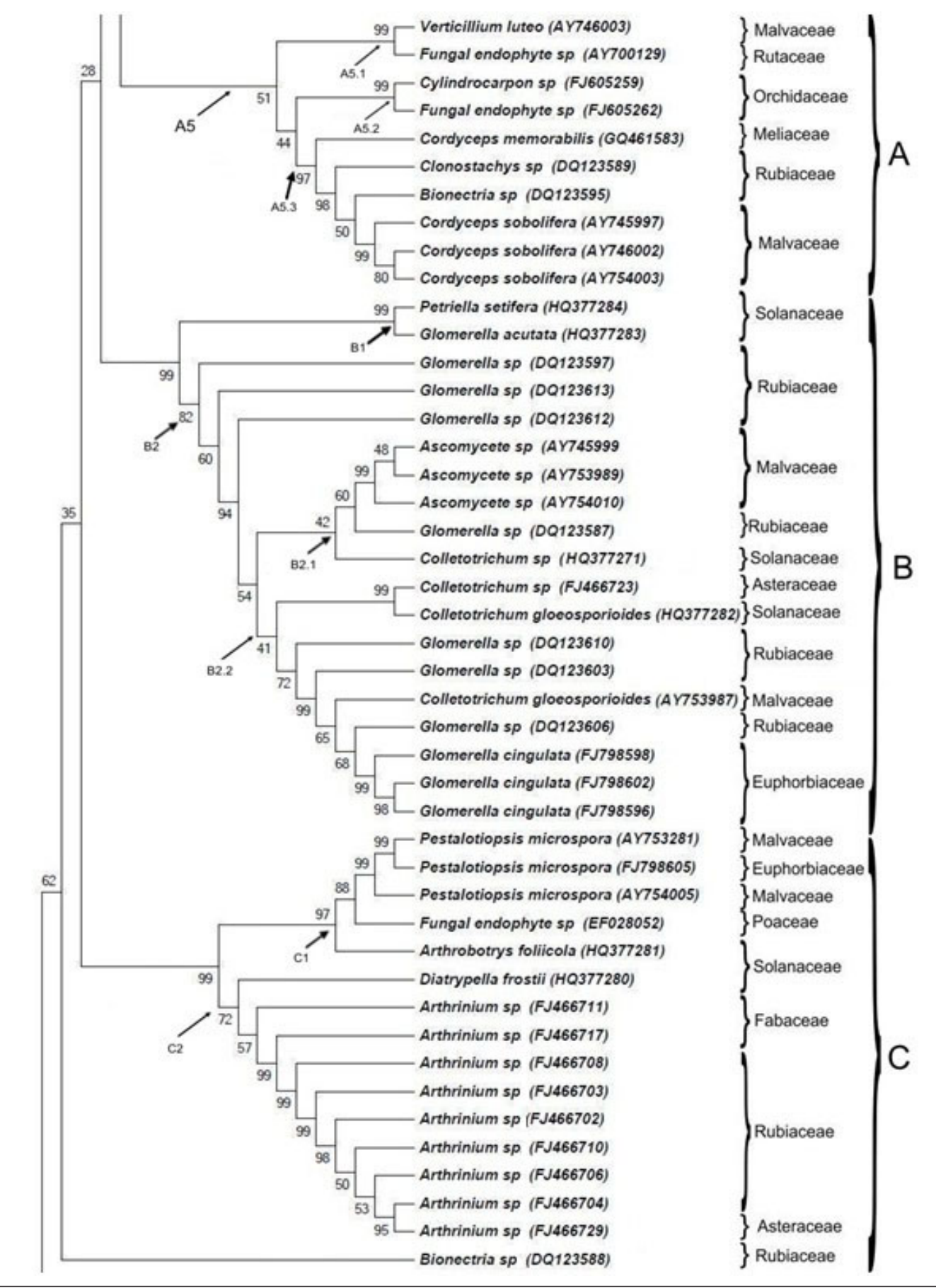

Continued on next page 
Figure 1. Continued.

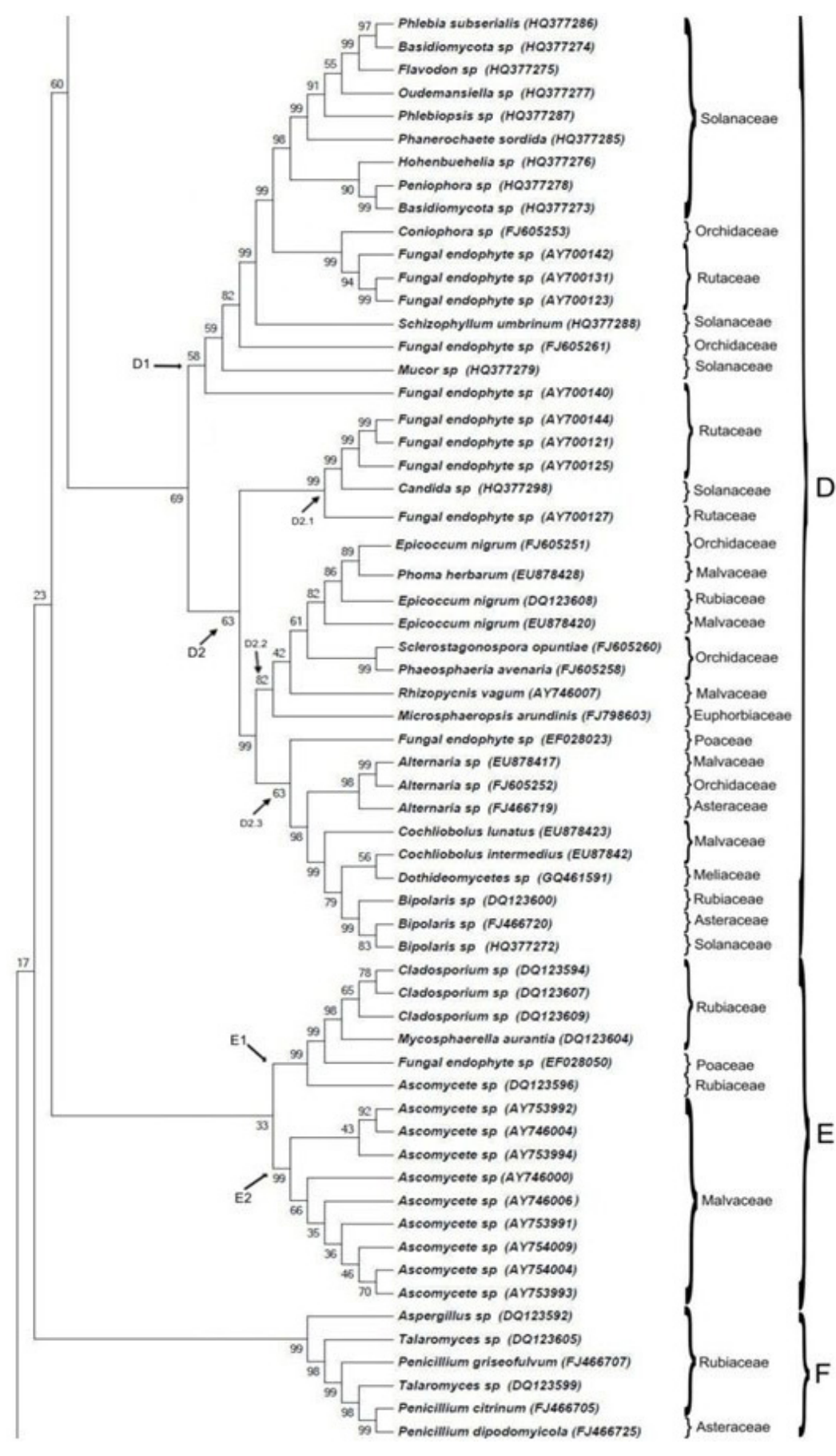

Continued on next page 
Figure 1. Continued.

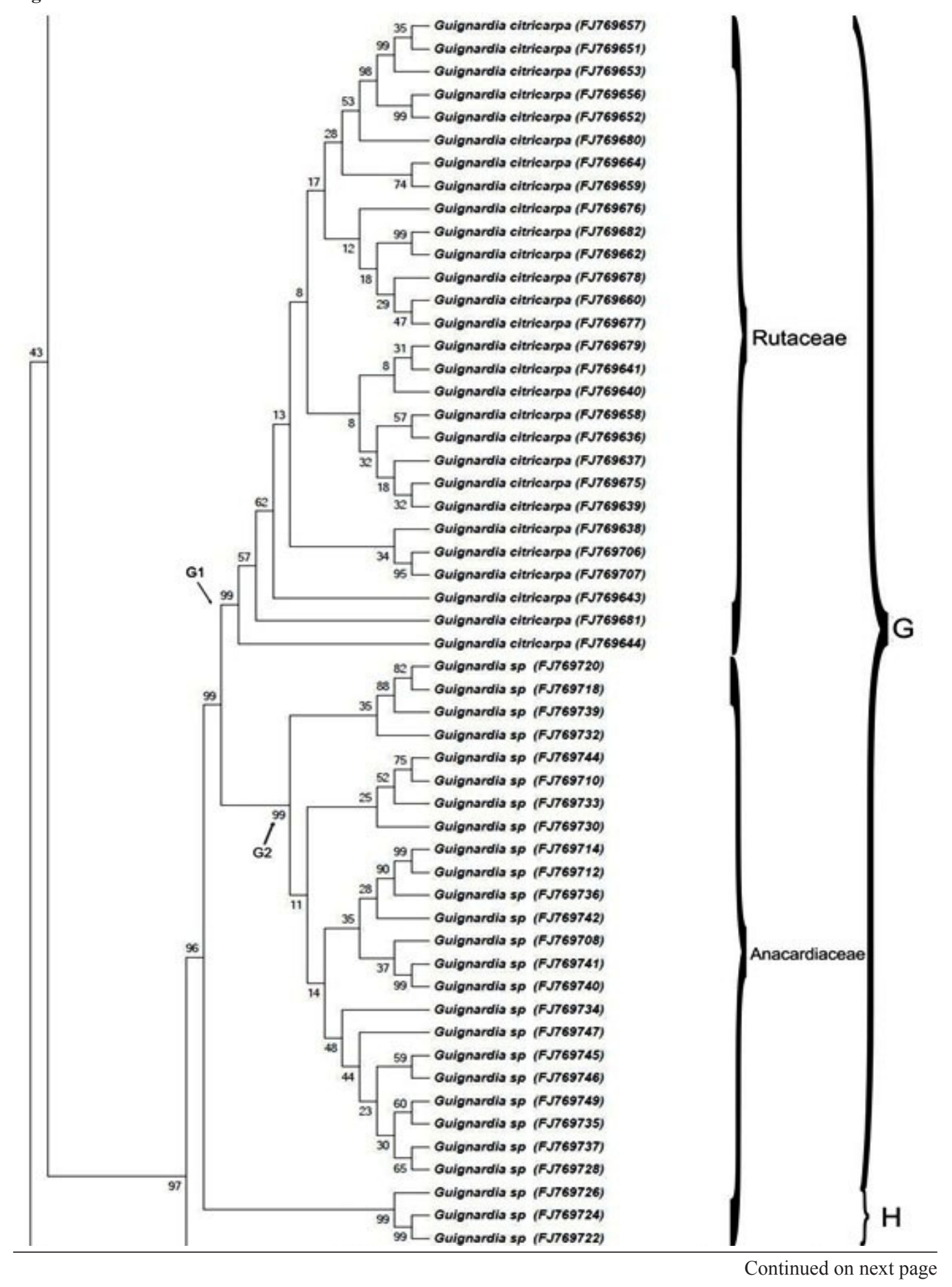


Figure 1. Continued.

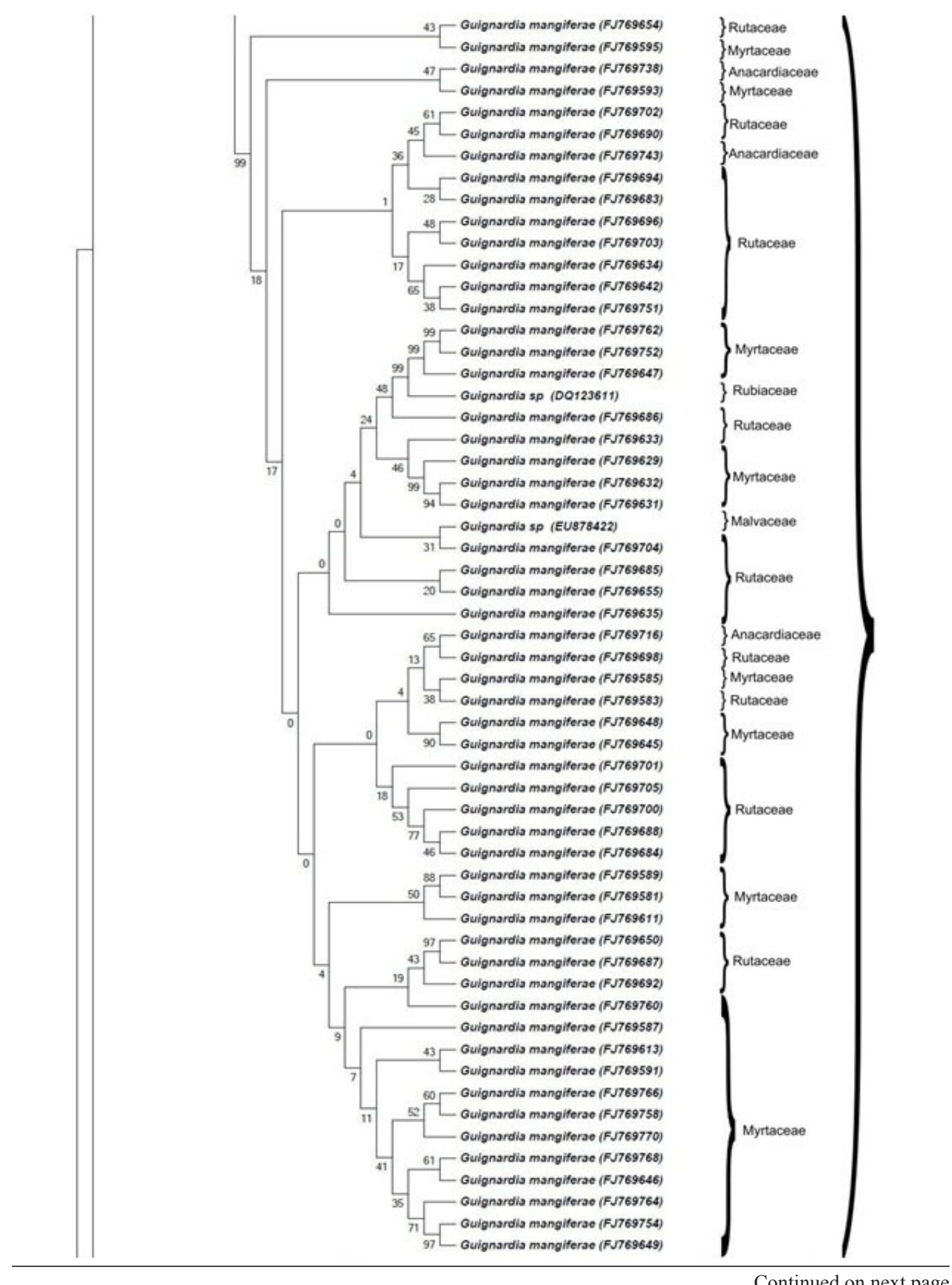

Continued on next page 
Figure 1. Continued.

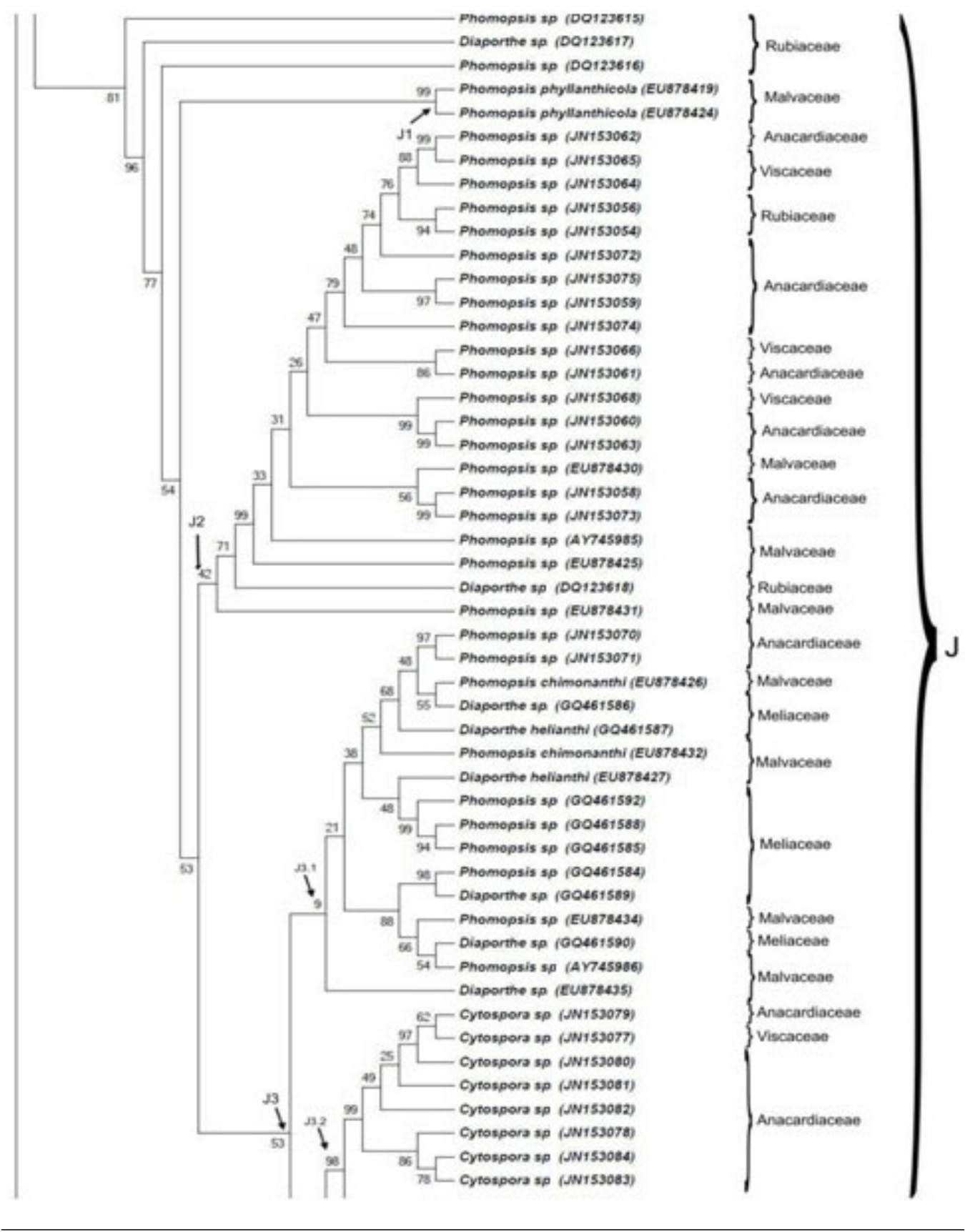

Continued on next page 
Figure 1. Continued.

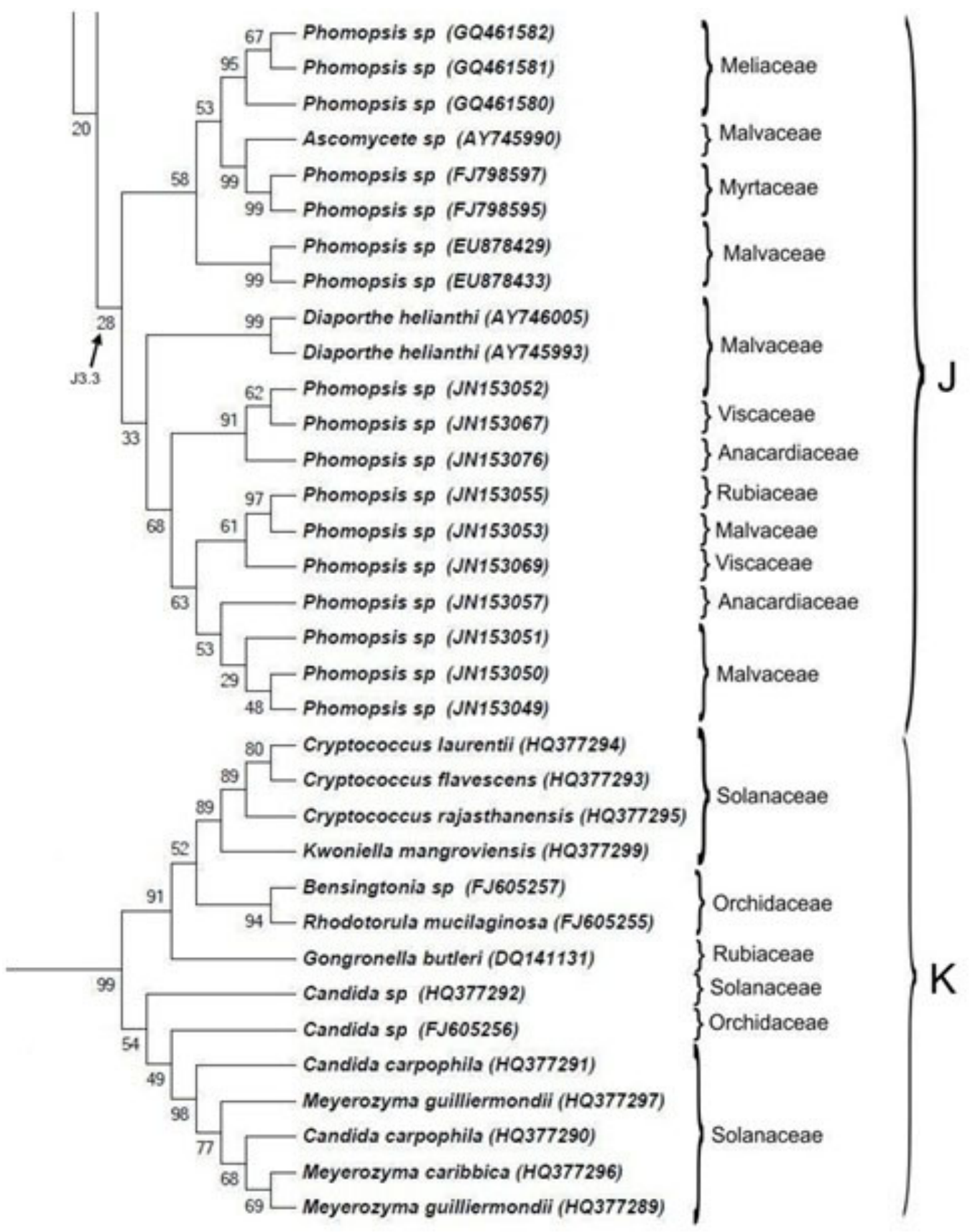




\section{Sequence alignment}

The sequences selected from GenBank were submitted to multiple alignment using Clustal-W (Altschul et al., 1990), MEGA 5 (Tamura et al., 2011), and the grouping neighborjoining method (Saitou and Nei, 1987) with 1000 bootstrapping (BP) repetitions for the construction of cladograms (Felsenstein, 1985).

\section{RESULTS AND DISCUSSION}

The plant families as well as the references used in endophytic diversity studies are listed in Table 1.

\begin{tabular}{|c|c|c|}
\hline Family & Isolated fungi & Reference \\
\hline Orchidaceae & $\begin{array}{l}\text { Hypocrea, Trichoderma, Fusarium, Gibberella, Coniophora, } \\
\text { Epicoccum, Sclerostagonospora, Bensingtonia, Rhodotorula, and Candida }\end{array}$ & (Vaz et al., 2009) \\
\hline Rubiaceae & $\begin{array}{l}\text { Trichoderma, Fusarium, Clonostachys, Bionectria, Glomerella, Arthrinium, } \\
\text { Epicoccum, Phaeosphaeria, Cladosporium, Mycosphaerella, Aspergillus, } \\
\text { Talaromyces, Penicillium, Guignardi, Phomopsis, Diaporthe, and Gongronella }\end{array}$ & $\begin{array}{l}\text { (Sette et al., 2006; Rosa et al., 2010; } \\
\text { Abreu et al., 2012) }\end{array}$ \\
\hline Euphorbiaceae & Fusarium, Myrothecium, Gibberella, and Glomerella & (Rocha et al., 2011) \\
\hline Malvaceae & $\begin{array}{l}\text { Fusarium, Gibberella, Nectria, Cordyceps, Colletotrichum, Phoma, } \\
\text { Epicoccum, Rhizopycnis, Alternaria, Diaporthe, Cochliobolus, } \\
\text { Guignardia, and Phomopsis }\end{array}$ & $\begin{array}{l}\text { (Rubini et al., 2005; } \\
\text { Bernardi-Wenzel et al., 2010; } \\
\text { Abreu et al., 2012) }\end{array}$ \\
\hline Meliaceae & Cordyceps, Phomopsi, and Diaporthe & (Rhoden et al., 2012) \\
\hline Solanaceae & $\begin{array}{l}\text { Petriella, Glomerella, Colletotrichum, Diatrypella, Phlebia, Flavodon, } \\
\text { Oudemansiella, Phlebiopsis, Phanerochaete, Hohenbuehelia, } \\
\text { Peniophora, Schizophyllum, Mucor, Candida, Cryptococcus, Kwoniella, } \\
\text { Bensingtonia, and Meyerozyma }\end{array}$ & (Vieira et al., 2012) \\
\hline Asteraceae & Colletotrichum, Arthrinium, and Penicillium & (Rosa et al., 2010) \\
\hline Fabaceae & Arthrinium & (Rosa et al., 2010) \\
\hline Rutaceae & Guignardia & (Gai et al., 2009; Wickert et al., 2009) \\
\hline Anacardiaceae & Guignardia, Phomopsis, and Cytospora. & (Abreu et al., 2012) \\
\hline Myrtaceae & Guignardia and Phomopsis & (Wickert et al., 2009) \\
\hline Viscaceae & Phomopsis and Cytospora & (Abreu et al., 2012) \\
\hline Poaceae & Fungal endophyte & (Stuart et al., 2010) \\
\hline
\end{tabular}

\section{Phylogenetic analysis through ITS sequencing}

The few studies on tropical endophytes that have been carried out are primarily descriptive, with some attention to their impact on estimates of global fungal diversity (Arnold et al., 2009). Cultured Ascomycota endophytes are distributed among the Sordariomycetes, Dothideomycetes, Eurotiomycetes, and Leotiomycetes. Arnold (2008) reviewed "designating functional taxonomic units", highlighting that BLAST searches of the NCBI GenBank database of ITS1-5,8S-ITS2 sequences are frequently used to identify endophytes and that ITS data are valued for species-level systematics. However, according to the author, these data may obscure cryptic species; therefore, caution is warranted in assigning identities to endophytes based on BLAST searches. As a result, using phylogenetic analysis with multiple information loci and, where possible, induction of sporulation is important.

The present in silico study showed an existing high diversity in fungal endophyte isolates from various host plants in diverse climatic regions in Brazil ranging from the most tropical zone of the Amazon region (Amazonas State) to a more temperate zone (São Paulo State). 
Arnold (2008) pointed out that many of the genera shared between temperate zones and the tropics represent fast-growing taxa that are rapidly and easily isolated using standard media.

The phylogenetic analysis in the present study (see Figure 1) was divided into 11 groups represented by keys (A, B, C, D, E, F, G, H, I, J, and K).

Groups A and B were represented by isolates of class Sordariomycetes and order Hypocreales. Group A (Sordariomycetes) was divided into 4 clades (A1, A2, A3, and A4), and these clades were divided into subclades. Class Sordariomycetes was represented by the largest monophyletic clades in the Ascomycota, with more than 600 genera and 3000 known species (Kirk et al., 2008). Members of the Sordariomycetes are cosmopolitan and function in almost all ecosystems as pathogens and endophytes of plants, arthropods, and mammals and in mycoparasites and saprobes involved in decomposition and nutrient cycling. Most plant pathogens in the Sordariomycetes are distributed in the orders Diaporthales, Hypocreales, Microascales, Ophiostomatales, Phyllachorales, and Xylariales (Alexopoulos et al., 1996).

The clade represented by arrow A1 is divided into 5 subclades (A1.1-A1.5). The subclade represented by arrow A.1.1 includes 2 fungi of genus Hypocrea isolated from family Orchidaceae and 2 of genus Trichoderma isolated from family Rubiaceae. The subclade A1.2 [93\% BP], includes 3 endophyte fungi of genus Trichoderma isolated from families Rubiaceae and Orchidaceae.

Subclade A1.3, with 99\% BP, includes genus Myrothecium isolated from family Euphorbiaceae and Fusarium isolated from family Orchidaceae. The branch represented by arrow A1.4 (31\% BP) identified the fungus Pseudofusarium purpureum isolated from family Malvaceae. Subclade A1.5 (99\% BP) groups 3 isolates from genus Fusarium isolated from family Malvaceae. Clade A2 (96\% of BP) is represented by species denominated Ascomycete from Theobroma cacao (Malvaceae).

Clade A3 (99\% BP) is represented by genera Fusarium, Nectria, and Fungal sp, all isolates from family Malvaceae. Clade A4 (86\% BP) has endophytes of genus Fusarium. These fungi were isolated from Rubiaceae, Malvaceae, Orchidaceae, and Euphorbiaceae. The isolates of genus Gibberella were obtained from Euphorbiaceae, Malvaceae, and Orchidaceae.

Clade A5 includes an isolate of genus Verticillium (order Glomerales) from family Malvaceae and an isolate denominated fungal endophyte from family Rutaceae with 99\% BP. Subclade A5.2 contains 2 fungi isolated from family Orchidaceae: 1 Cylindrocarpon (Hypocreales) and 1 denominated fungal endophyte sp subclade A5.3 (97\% BP) is represented by genus Cordyceps (Hypocreales order) isolated from families Meliaceae and Malvaceae. This subclade also includes isolates from genera Clonostachys (Hypocreales order) and Bionectria (Hypocreales order) from family Rubiaceae.

Group B (class Sordariomycetes; 99\% BP) is divided into 2 clades. Clade B1 (99\% $\mathrm{BP}$ ) is represented by isolates Petriella setifera (order Microascales) and Glomerella acutata (order Glomerales), both isolated from family Solanaceae. Clade B2 constitutes 3 fungi from genus Glomerella (isolated from family Rubiaceae), 3 Ascomycete sp isolated from family Malvaceae, genus Glomerella isolated from family Rubiaceae, and Colletotrichum (order Glomerales) isolated from family Solanaceae. Subclade B2.2, with $41 \%$ BP, includes genus Colletotrichum isolated from Asteraceae, Solanaceae, and Malvaceae and genus Glomerella isolated from Rubiaceae and Euphorbiaceae.

Group C, with 99\% BP, is subdivided into 2 clades (C1 and C2). Clade C1 includes 3 fungi of genus Pestalotiopsis (order Xylariales) isolated from families Malvaceae and Eu- 
phorbiaceae. In this clade, one fungus denominated fungal endophyte from family Poaceae and another isolate Arthrobotrys (order Orbiliaceae) from family Solanaceae were also found.

Clade C2, with 72\% BP, has 10 isolates: 1 of genus Diatrypella (order Xylariales) isolated from Solanaceae and 9 of genus Arthrinium (family Apiosporaceae) isolated from families Fabaceae, Rubiaceae, and Asteraceae. The isolate Bionectria sp (order Hypocreales) from family Rubiaceae was not linked to group C.

Group D (69\% BP) is divided into 2 main clades. Clade D1 is represented by Phlebia (order Corticiales), Flavodon (order Polyporales), Oudemansiella (order Agaricales), Phlebiopsis (order Polyporales), Phanerochaete (order Agaricales), and 1 Basidiomycota isolated from family Solanaceae. These 5 genera belong to class Agaricomycetes. Hohenbuehelia (order Agaricales) and Peniophora (order Russulales), belonging to class Agaricomycetes and Basidiomycota isolated from family Solanaceae were also found. Genus Coniophora (order Boletales) and 3 fungi denominated fungal endophyte were isolated from family Rutaceae (99\% BP). Four additional isolates, 1 of each genera Schizophyllum (order Agaricales) and Mucor (order Mucorales), both isolated from family Solanaceae, and 2 isolates denominated fungal endophyte isolated from families Orchidaceae and Rutaceae are also included.

Clade D2 (63\% BP) is divided into 3 subclades (D2.1, D2.2, and D2.3). D2.1 is composed of 3 fungi denominated fungal endophyte isolated from family Rutaceae and 1 Candida (order Saccharomycetales) isolated from family Solanaceae. Subclade D2.2 (83\% BP) is formed by 8 isolates: 3 fungi of genus Epicoccum (order Pleosporales) isolated from families Orchidaceae, Rubiaceae, and Malvaceae; 1 genus Phoma (order Pleosporales) isolated from family Malvaceae; 1 genus Sclerostagonospora (order Pleosporales) isolated from family Orchidaceae, 1 genus Rhizopycnis (class Dothideomycetes) isolated from family Malvaceae; and 1 genus Microsphaeropsis (Pleosporales) isolated from family Euphorbiaceae. Rhoden et al. (2012) isolated endophyte fungi of Trichilia elegans belonging to the classes Sordariomycetes and Dothideomycetes, but the main genera isolated were Phomopsis and Cordyceps.

Subclade D2.3 is composed of 10 isolates: 1 fungal endophyte isolated from family Poaceae and 3 phylogenetically related fungi from genus Alternaria (order Pleosporales) isolated from families Malvaceae, Orchidaceae, and Asteraceae. In sequence, the genus $\mathrm{Co}$ chliobolus (order Pleosporales), with 2 isolates from family Malvaceae, 1 denominated Dothideomycete sp isolated from family Meliaceae, and 3 genus Bipolaris (order Pleosporales) isolated from families Rubiaceae, Asteraceae and Solanaceae were found.

Group E (33\% BP) is subdivided into 2 clades (E1 and E2). Clade E1 (99\% BP) has 6 isolates: 3 fungi of genus Cladosporium (order Capnodiales) isolated from family Rubiaceae, 1 genus Mycosphaerella (order Capnodiales) isolated from family Rubiaceae, 1 fungus denominated fungal endophyte isolated from family Poaceae, and 1 Ascomycete isolated from family Rubiaceae. Clade E2 (99\% BP) comprised 9 fungi denominated Ascomycete sp isolated from family Malvaceae.

Group F (99\% BP) is represented by 6 isolates: 1 genus Aspergillus (order Eurotiales) isolated from family Rubiaceae, 2 genus Talaromyces (order Eurotiales) isolated from family Rubiaceae, and 3 Penicillium (order Eurotiales) isolated from families Rubiaceae and Asteraceae. Group G (99\%BP) is subdivided into 2 clades (G1 with 99\% BP, and G2 with 99\% BP). G1 contains isolates of Guignardia citricarpa (order Botryosphaeriales) isolated from family Rutaceae. Clade G2 contains several endophytes belonging to Guignardia sp isolated from Anacardiaceae. Group H (99\% BP) contains other Guignardia sp isolated from family Anacardiaceae. 
Group I is represented by genus Guignardia (order Dothideomycete) isolated from families Rutaceae, Anacardiaceae, Myrtaceae, Rubiaceae, and Malvaceae. Group J is divided into 3 main clades (J1, J2, J3). Clade J1 is formed by 2 endophytic fungi of genus Phomopsis isolated from family Malvaceae. The genera Phomopsis and Diaporthe (order Diaporthales) isolated from families Rubiaceae and Malvaceae were not close to J1. Clade J2 is composed of Phomopsis isolated from families Anacardiaceae, Viscaceae, Rubiaceae, and Malvaceae.

Abreu et al. (2012) investigated 36 strains of Phomopsis spp and Cytospora-like fungi and endophytes obtained from various host plants in Brazil using metabolite profiling based on high-performance liquid chromatography-ultraviolet/liquid chromatography-mass spectrometry and cluster analysis. Strains were also subjected to phylogenetic analyses based on ITS rDNA. Tree topologies generated with a Bayesian consensus phylogenetic tree from a nucleotide alignment of the ITS rDNA region (using MEGA 5) and maximum parsimony analyses (using the close-neighbor-interchange algorithm in MEGA 5) were coincident in most parts.

Clade J3 (53\% BP) is subdivided into subclades J3.1 (9\%BP), J3.2 (99\% BP), and J3.3 (28\% BP). Subclade J3.1 is organized by genera Phomopsis and Diaporthe isolated from families Anacardiaceae, Malvaceae, and Meliaceae. Subclade J3.2 is formed by Cytospora (order Diaporthales) isolated from families Anacardiaceae and Viscaceae. Subclade J3.3 is represented by genus Phomopsis isolated from families Meliaceae, Myrtaceae, Malvaceae, Viscaceae, Anacardiaceae, and Rubiaceae.

Group K is constructed with 14 fungal endophytes: 3 genus Cryptococcus (order Tremellales) isolated from family Solanaceae, 1 genus Kwoniella (order Tremellales) isolated from family Solanaceae, 1 genus Bensigtonia (class Agaricostilbomycetes) isolated from family Orchidaceae, 1 fungal endophyte of genus Rhodotorula (order Microbotryomycetes), and 1 genus Gongronella (order Mucoromycotina). Also included were 4 endophytes belonging to genus Candida (order Saccharomycetales) isolated from families Rubiaceae, Solanaceae, and Orchidaceae and 3 additional fungi of genus Meyerozyma (order Saccharomycetales) isolated from family Solanaceae. Notably, the Candida sp isolate (HQ377298) from family Solanaceae was not clustered with the other Candida spin group K; however, all isolates were obtained from the same host plant.

The majority of studies of endophytic fungi have used leaves, and the proportion of endophyte infection in leaves appears to increase from the arctic to the tropics, although most plant communities have not yet been sampled. In temperate zones, the frequency of endophyte infection is influenced by precipitation, humidity, elevation, irradiance, and air pollution, but the roles of these factors have not been fully assessed in the tropics - in particular, tropical savannas and dry forests. In addition, the canopies of moist or wet forests represent unique environmental conditions characterized by high irradiance, high temperature, and geographic congruence with endophyte-rich forests.

Bernardi-Wenzel et al. (2010) verified that rDNA sequence analysis associated with the traditional method of fungus identification via cytological analysis can identify several endophytic fungi isolated from Luehea divaricata. This finding demonstrates that both tools are effective in the study of endophyte taxonomy. With the dendrogram generated with the unweighted pair group method with arithmetic means using the Yule coefficient (using MEGA 5 program), Abreu et al. (2012) classified 36 strains into 6 chemotypes and showed that sequences corresponding to strains classified in various chemotypes formed single phylogenetic lineages or closely related groups in chemical and molecular analyses. Accordingly, metabo- 
lite profiling and chemical classification may be used to support phenotypic species recognition in Phomopsis and closely related Diaporthales.

In this study, using in silico studies of phylogenetic analyses of rDNA sequences (from a diverse group of ITS1-5,8S-ITS2 sequences obtained from endophytes isolated in different regions of Brazil and published and submitted to GenBank between 2005 and 2012), we concluded that the GenBank database is sufficiently robust for application in future studies in which the molecular identification of endophyte based on rDNA sequences is necessary. Our data corroborate that studies using ITS sequences obtained via sequencing methodology are sufficient for fungal diversity analyses. Although the current study showed that a few endophytes could not have been correctly identified because of inconsistencies in their location in the phylogenetic tree, more than $98 \%$ of the ITS sequences deposited in GenBank were consistent with the identification of related genera, as shown by the tree generated with MEGA 5. This study highlights the importance of future phylogenetic studies in the conservation of endophytic diversity in Brazil.

\section{REFERENCES}

Abreu LM, Costa SS, Pfenning LH, Takahashi JA, et al. (2012). Chemical and molecular characterization of Phomopsis and Cytospora-like endophytes from different host plants in Brazil. Fungal Biol. 116: 249-260.

Alexopoulos CJ, Mims CW and Blackwell M (1996). Introductory Mycology. John Wiley \& Sons Inc., New York.

Altschul SF, Gish W, Miller W, Myers EW, et al. (1990). Basic Local Alignment Search Tool. J. Mol. Biol. 215: 403-410.

Arnold AE (2008). Tropical Forest Community Ecology. In: Endophytic Fungi: Hidden Components of Tropical Community Ecology (Carson W and Schnitzer S, eds.). Blackwell Scientific, Inc., Malden, 254-271.

Arnold AE, Henk DA, Eells RL, Lutzoni F, et al. (2007). Diversity and phylogenetic affinities of foliar fungal endophytes in loblolly pine inferred by culturing and environmental PCR. Mycologia 99: 185-206.

Arnold AE, Miadlikowska J, Higgins KL, Sarvate SD, et al. (2009). A phylogenetic estimation of trophic transition networks for ascomycetous fungi: are lichens cradles of symbiotrophic fungal diversification? Syst. Biol. 58: 283-297.

Azevedo JL, Maccheroni W Jr, Pereira JO and Araújo WL (2000). Endophytic microorganisms: a review on insect control and recent advances on tropical plants. EJB: Eletron. J. Biotechnol. 3: 40-65.

Bellemain E, Carlsen T, Brochmann C, Coissac E, et al. (2010). ITS as an environmental DNA barcode for fungi: an in silico approach reveals potential PCR biases. BMC Microbiol. 10: 189.

Bernardi-Wenzel J, Garcia A, Filho CJ, Prioli AJ, et al. (2010). Evaluation of foliar fungal endophyte diversity and colonization of medicinal plant Luehea divaricata (Martius et Zuccarini). Biol. Res. 43: 375-384.

Chen SH, Lin CY and Kuo CM (2005). In silico analysis of crustacean hyperglycemic hormone family. Mar. Biotechnol. 7: 193-206.

Felsenstein J (1985). Confidence limits on phylogenies: an approach using the bootstrap. Evolution 39: 783-791.

Gai CS, Lacava PT, Maccheroni W Jr, Glienke C, et al. (2009). Diversity of endophytic yeasts from sweet orange and their localization by scanning electron microscopy. J. Basic Microbiol. 49: 441-451.

Gilbert LB, Chae L, Kasuga T and Taylor JW (2011). Array Comparative Genomic Hybridizations: assessing the ability to recapture evolutionary relationships using an in silico approach. BMC Genomics 12: 456.

Higgins KL, Arnold AE, Miadlikowska J, Sarvate SD, et al. (2007). Phylogenetic relationships, host affinity, and geographic structure of boreal and arctic endophytes from three major plant lineages. Mol. Phylogenet. Evol. 42: 543-555.

Jasinski JPP and Payette S (2007). Holocene occurrence of Lophodermium piceae, a black spruce needle endophyte and possible paleoindicator of boreal forest health. Quaternary Res. 67: 50-56.

Kirk PM, Cannon PF, Minter DW and Stalpers JA (2008). Ainsworth \& Bisby's Dictionary of the Fungi. CAB International, Wallingford.

Kogel KH, Franken P and Huckelhoven R (2006). Endophyte or parasite - what decides? Curr. Opin. Plant Biol. 9: 358-363.

Koulman A, Lane GA, Christensen MJ, Fraser K, et al. (2007). Peramine and other fungal alkaloids are exuded in the guttation fluid of endophyte-infected grasses. Phytochemistry 68: 355-360.

MMA/SBF. Ministério do Meio Ambiente SdBeF (2002). Biodiversidade Brasileira: Avaliação e Identificação de Áreas e Ações Prioritárias para Conservação, Utilização Sustentável e Repartição de Benefícios da Biodiversidade Brasileira. 
SBF, Brasília. Available at [http://www.mma.gov.br/estruturas/chm/_arquivos/biodivbr.pdf]. Accessed May 15, 2012.

Palsson B (2000). The challenges of in silico biology: Moving from a reductionist paradigm to one that views cells as systems will necessitate changes in both the culture and the practice of research. Nat. Biotechnol. 18: 1147-1150.

Pamphile JA and Azevedo JL (2002). Molecular characterization of endophytic strains of Fusarium verticillioides (Fusarium moniliforme) from maize (Zea mays L.). World J. Microbiol. Biotechnol. 18: 391-396.

Rhoden SA, Garcia A, Rubin Filho CJ, Azevedo JL, et al. (2012). Phylogenetic diversity of endophytic leaf fungus isolates from the medicinal tree Trichilia elegans (Meliaceae). Genet. Mol. Res. 11: 2513-2522.

Rocha ACS, Garcia D, Uetanabaro APT, Carneiro RTO, et al. (2011). Foliar endophytic fungi from Hevea brasiliensis and their antagonism on Microcyclus ulei. Fungal Divers. 47: 75-84.

Rosa LH, Gonçalves VN, Caligiorne RB, Alves TMA, et al. (2010). Leishmanicidal, trypanocidal, and cytotoxic activities of endophytic fungi associated with bioactive plants in Brazil. Braz. J. Microbiol. 41: 420-430.

Rubini MR, Silva-Ribeiro RT, Pomella AW, Maki CS, et al. (2005). Diversity of endophytic fungal community of cacao (Theobroma cacao L.) and biological control of Crinipellis perniciosa, causal agent of Witches' Broom Disease. Int. J. Biol. Sci. 1: 24-33.

Saikkonen K, Wali P, Helander M and Faeth SH (2004). Evolution of endophyte-plant symbioses. Trends Plant Sci. 9: $275-280$

Saitou N and Nei M (1987). The neighbor-joining method: a new method for reconstructing phylogenetic trees. Mol. Biol. Evol. 4: 406-425.

Sette LD, Passarini MRZ, Delarmelina C, Salati F, et al. (2006). Molecular characterization and antimicrobial activity of endophytic fungi from coffee plants. World J. Microb. Biot. 22: 1185-1195.

Souza AQL, Souza ADL, Astolfi-Filho S, Belém-Pinheiro ML, et al. (2004). Atividade antimicrobiana de fungos endofíticos isolados de plantas tóxicas da Amazônia: Palicourea longiflora (Aubl.) rich e Strychnos cogens bentham. Acta Amaz. 34: 185-195.

Strobel GA (2003). Endophytes as sources of bioactive products. Microbes Infect. 5: 535-544.

Strobel GA, Hess WM, Ford E, Sidhu RS, et al. (1996). Taxol from fungal endophytes and the issue of biodiversity. J. Ind. Microbiol. Biot. 17: 417-423.

Stuart RM, Romao AS, Pizzirani-Kleiner AA, Azevedo JL, et al. (2010). Culturable endophytic filamentous fungi from leaves of transgenic imidazolinone-tolerant sugarcane and its non-transgenic isolines. Arch. Microbiol. 192: 307-313.

Tamura K, Peterson D, Peterson N, Stecher G, et al. (2011). MEGA5: molecular evolutionary genetics analysis using maximum likelihood, evolutionary distance, and maximum parsimony methods. Mol. Biol. Evol. 28: 2731-2739.

Vaz AB, Mota RC, Bomfim MR, Vieira ML, et al. (2009). Antimicrobial activity of endophytic fungi associated with Orchidaceae in Brazil. Can. J. Microbiol. 55: 1381-1391.

Victoria FC, da Maia LC and de Oliveira AC (2011). In silico comparative analysis of SSR markers in plants. BMC Plant Biol. 11: 15.

Vieira ML, Hughes AF, Gil VB, Vaz AB, et al. (2012). Diversity and antimicrobial activities of the fungal endophyte community associated with the traditional Brazilian medicinal plant Solanum cernuum Vell. (Solanaceae). Can. J. Microbiol. 58: 54-66.

Wickert E, de Goes A, de Macedo Lemos EG, de Souza A, et al. (2009). Relações filogenéticas e diversidade de isolados de Guignardia spp oriundos de diferentes hospedeiros nas regiões ITS1-5,8S-ITS2. Rev. Bras. Frutic. 31: 360-380. 